\title{
Evaluation of amplitude of accommodation in a presbyopic patient undergoing stimulation of sizhukong acupuncture point (th23)-case report
}

\section{Introduction}

The term "presbyopia" derives from Aristotle's description about observation of persons that could to see well at distance, but poorly at near after 40 years old of age. ${ }^{1}$ Historically, the term presbyopia was used to describe the condition where the near point has receded too far from the eye for normal near-vision tasks. It is the most common refractive error in adulthood and is caused by gradual decrease in the amplitude of accommodation, ${ }^{2}$ observed by about 40 years of age. ${ }^{3}$ Early symptoms are difficulty in focusing on nearby objects under inadequate light and at the end of the day and progress to blurred vision at near. Presbyopia can be corrected by wearing multifocal or reading glasses, contact lenses ${ }^{4}$ or surgery in some cases. ${ }^{1}$ The physical mechanism of loss of accommodation remains unknown, but Helmholtz's hypothesis ${ }^{5,6}$ is one of the most accepted theories that try to explain it. According to the Helmholtz's model, the contraction of the ciliary muscle would allow relaxation of crystalline capsule, which, by elastic contraction, would deform the lens, increasing its thickness and, therefore, the optical power. When the ciliary muscle relaxes, the zonular tension will increase, tensioning the lens. This tension reduces its anteroposterior dimension and increases the focal distance. The aim of acupuncture is to treat health problems by application of stimuli through the skin, with insertion of needles at specific points. ${ }^{7,8}$ The mechanisms of action of acupuncture are unknown, but evidences point to possible neurochemical phenomena. ${ }^{9-11}$ Ancient reports in the literature of Traditional Chinese Medicine (TCM) show that the stimulation of certain acupuncture points can improve visual acuity, particularly in cases of myopia and presbyopia. ${ }^{12}$ To determine the effects of near visual acuity, we chose the Sizhukong acupuncture point (TH23), among other related points such ST4, B2, GB 37, ST 30 and L3. ${ }^{13}$ This article reports a clinical case of a presbyopic subject undergoing stimulation of the Sizhukong acupuncture point (TH23) and analyzes the behaviour of her vision at near after needling.

\section{Case report}

GAL., Female, 56 years old, Brazilian, native of Guaratinga-Ba, from São Paulo, housewife, elementary school incomplete, catholic. This patient complaint of progressive loss of vision at near for about fifteen years ago. She refers low vision at near with her current reading glasses $(+1.50 \mathrm{SPH})$. There is not pathological personal history, regular use of medication, or surgical history. The patient was orthophoric
Volume 8 Issue I - 2018

\author{
Gilvano Amorim Oliveira \\ Medicine School PUCCAMP University, Brazil
}

Correspondence: Gilvano Amorim Oliveira, Medicine School PUCCAMP University, Av. Onze de Agosto, no. 736 Sala 22,Vila Clayton.Valinhos/SP, CEP 13276I30, Brazil, Email drgilvanoamorim@hotmail.com

Received: May 12, 2017 | Published: January 19, 2018

and remained orthophoric under cover/uncover test. Biomicroscopy and fundoscopy were normal. It could be observed phacosclerosis, but no cataracts. Tonometry by aplanation revealed $12 \mathrm{mmHg}$ in both eyes (measurement at 8:50 a.m.). Dynamic esquiascopy: OD: +0.25 +0.2590 with visual acuity of $20 / 20$ and OS: -0.25 SPH with visual acuity of 20/20. Static esquiascopy (Cycloplegia was performed before acupuncture session.): OD: $+0.25 \mathrm{SPH}$ and OS: $+0.25 \mathrm{SPH}$. For cycloplegia, we used cyclopentolate drops. Visual acuity at near without addition was J5 on Jaeger's table. In the Table 1 below the parameters of the patient's ophthalmic examination at first day are presented: Patient was under gone to bilateral needling of Sizhukong acupuncture point (TH23) with 25 X 40mmstainless steel needle at 7:20 a.m. The acupuncture's technic consisted of to prick the selected point before to leave needle resting for 20 minutes. After acupuncture session, the patient remained 20/20 in both eyes and gradually showed gain of visual acuity at near until to reach J1 line on Jaeger's table, without addition.No miosis was observed associated with gain of the amplitude of accommodation. After acupuncture session, visual acuity, amplitude of accommodation, vision at near and addition were evaluated at 7:50 a.m., 9:00 a.m., 14 p.m., 16 p.m., and 20 p.m. The findings of second day of examination are displayed in the next Table 2. It is notorious the gain of the accommodation amplitude of $3.50 \mathrm{D}$ after the needling of Sizhukong acupuncture point (TH23). Visual acuity at near without addition was increased to J1 on Jaeger's table. In the next table, it is displayed visual acuity, amplitude de accommodation, vision at near, and addition (Table 3).

Table I Refraction parameters-static and dynamic refraction

\begin{tabular}{lllll}
\hline Eye & Visual acuity & Dynamic refraction & Static refraction & Keratometry \\
\hline OD & $20 / 20$ & $+0.25+0.2590$ & $+0.25 \mathrm{SPH}$ & $45.00 \times 45.00180$ \\
OS & $20 / 20$ & $+0.25 \mathrm{SPH}$ & $+0.25 \mathrm{SPH}$ & $45.00 \times 45.00180$ \\
\hline
\end{tabular}


Table 2 Visual acuity, vision at near and addition after Sizhukong's needling

\begin{tabular}{|c|c|c|c|c|c|}
\hline Hour & $\begin{array}{l}\text { Time elapsed after } \\
\text { acupuncture session }\end{array}$ & Visual acuity & $\begin{array}{l}\text { Amplitude of } \\
\text { accommodation }\end{array}$ & $\begin{array}{l}\text { Vision at near } \\
\text { without correction }\end{array}$ & Addition to gain $\mathrm{Jl}$ vision \\
\hline 7:00 a.m. & $\longrightarrow$ & $20 / 20$ & $1.25 \mathrm{D}$ & $\mathrm{J} 5$ & $+2.50 \mathrm{D}$ \\
\hline 7:50 a.m. & $20 \mathrm{~min}$. & $20 / 20$ & $4.75 \mathrm{D}$ & J & $+0.00 \mathrm{D}$ \\
\hline 9:00 a.m. & Ih 40 min. & $20 / 20$ & $4.25 \mathrm{D}$ & I & $+0.00 \mathrm{D}$ \\
\hline |4:00 p.m. & $6 \mathrm{~h} 40 \mathrm{~min}$. & $20 / 20$ & $4.00 \mathrm{D}$ & J & $+0.25 \mathrm{D}$ \\
\hline 16:00 p. m. & $8 \mathrm{~h} 40 \mathrm{~min}$. & $20 / 20$ & $2.75 \mathrm{D}$ & $\mathrm{J} 2$ & $+0.75 \mathrm{D}$ \\
\hline 20:00 p. m. & $12 \mathrm{~h} 40 \mathrm{~min}$. & $20 / 20$ & $2.00 \mathrm{D}$ & J4 & $+1.50 \mathrm{D}$ \\
\hline
\end{tabular}

Table 3 Visual acuity, vision at near and addition 7 days after sizhukong's needling

\begin{tabular}{|c|c|c|c|c|}
\hline Hour & Visual acuity & Amplitude of accommodation & Vision at near without correction & Addition to gain $\mathrm{JI}$ vision \\
\hline 7:00 a.m. & $20 / 20$ & I.75D & $\mathrm{J} 5$ & $+2.50 \mathrm{D}$ \\
\hline 7:50 a.m. & $20 / 20$ & $\mathrm{I} .50 \mathrm{D}$ & J4 & $+2.25 \mathrm{D}$ \\
\hline 9:00 a.m. & $20 / 20$ & $\mathrm{I} .50 \mathrm{D}$ & $\mathrm{J} 5$ & $+2.50 \mathrm{D}$ \\
\hline 14:00 p.m. & $20 / 20$ & I.25 D & $\mathrm{J} 5$ & $+2.50 \mathrm{D}$ \\
\hline I6:00 p. m. & $20 / 20$ & $\mathrm{I} .50 \mathrm{D}$ & J4 & $+2.00 \mathrm{D}$ \\
\hline 20:00 p. m. & $20 / 20$ & I.75 D & $\mathrm{J} 5$ & $+2.50 \mathrm{D}$ \\
\hline
\end{tabular}

\section{Discussion}

This patient was examined on three different occasions. On the first day, she underwent a complete ophthalmologic exam, including cycloplegia to obtain the static refraction parameters and fundoscopy findings. On the second, 7 days later, the patient was underwent an acupuncture session and her parameters were evaluated during 12 hours. Studies demonstrate variation of the amplitude of accommodation throughout the day. ${ }^{14,15}$ To ensure that the increase in accommodation amplitude observed in this case was not a result of circadian variation, we re-examined the patient seven days later after acupuncture. At each evaluation a new kind of Jaeger's table was used to prevent the patient from would respond through training and memorization. The amplitude of accommodation is the maximum value of increasing diopter power to promote near vision. ${ }^{16}$ Loss of accommodation capacity is the main characteristic of presbyopia. The amplitude of accommodation can be measured in diopters (D) and represents the inverse of the distance of the fixation in meters. For evaluation of the amplitude of accommodation in this case, we used Sheard's technique. ${ }^{16-18}$ The amplitude of accommodation presented increasing of $3.50 \mathrm{D}$ after the needling. The near visual acuity changed, until the patient reached acuity of J1 on Jaeger's table. The patient's description was that she had the feeling of a photographic zoom that made near vision or clear, or blurred. About ten minutes focusing her eyes on Jaeger's table, she reached J1.

This patient presented a surprising response to acupuncture of the Sizhukong point, with gain of 3.50 D in amplitude of accommodation. The Sizhukong point (Sizhukong means "Silk Bamboo Hole" in Chinese) is located in the depression at the lateral end of the eyebrow, in a bony notch between the frontal process of zygomatic and the zygomatic process of the frontal. ${ }^{8-19,20}$ This acupuncture point is related to the orbicularis muscle and its area is vascularized by the frontal branches of the zygomatic orbital artery. It is sensitive territory of the lacrimal nerve, one of the divisions of the trigeminal branch V1. There is also contribution of the zygomatic temporal and zygomatic facial nerves (branches of the V2 portion of the trigeminal nerve) and the temporal branch of the facial nerve.We performed Bird pecking technic. ${ }^{17,18}$ This technic consists of to manipulate the needle up and down, like a Bird pecking the ground. We spent one minute each side manipulating the needle, before to leave it resting. According to TCM's classical writings, this technique enhances the effects of acupuncture. In our personal experience, the result of TH 23 needling without manipulation has a poorer outcome in near visual acuity. The Sizhukong point is last point of the Triple Heater Meridian (TH). ${ }^{21}$ This meridian originates from the tip of the fifth finger passes between the knuckles of the fourth and fifth metacarpal bones until the wrist. From wrist, it ascends between radius and ulna, through the tip of the elbow, and up the back of the arm to the shoulder. It goes forward into the chest, re-emerging at the collarbone. From collarbone, the meridian ascends the side of the neck and around the back of the ear to get the lateral end of the eyebrow. According to TCM, the Triple Heater (TH) meridian improves visual acuity, illuminates the eyes, cleans the heat of the head and face, and disperses the wind and the heat, and relief the pain. The main clinical indications of this meridian are reduction of fever, treatment of redness of the eyes, eyelid edema and chemosis, palpebral tremor, presbyopia, glaucoma, manic psychosis, and epilepsy. ${ }^{8}$

We did not find in the scientific literature any report similar to what we present in this article, with a serial measuring of amplitude of accommodation and visual acuity after needling. The literature of traditional Chinese Medicine refers to the stimulation of acupuncture points for presbyopia, such as Suzhukong point. ${ }^{11}$ However, we did not find any explanation that could demonstrate the mechanism of the increase of the amplitude of accommodation, with gain of near visual acuity at near. Faced with this unknowing we can only consider conjectures. First, the lens could have moved anteriorly. However, 
we would not be able to explain the mechanism of this displacement Another possibility is the stimulation of ciliary muscle contractility. Micro dialysis studies of acupuncture points ${ }^{22}$ demonstrate that needle stimulation releases certain substances locally. Eventually, release of some substance could be related to the gain of amplitude of accommodation due to contraction of ciliary muscle. Blurred vision of nearby objects triggers the reflex of accommodation. ${ }^{6}$ This reflex consists in the accommodation when a blurred near object is observed and can be provoked by asking the patient to look away and then fix an object placed about $30 \mathrm{~cm}$ from their eyes. ${ }^{23}$ The patient with presbyopia loses this reflex response. ${ }^{24}$ The contraction of the ciliary muscle represents the peripheral mechanism of accommodation, secondary to a central mechanism. This central mechanism is activated by blurred image of near objects. Through the optic pathways, this stimulus reaches areas 17 and continues until area 19 where the efferent response loop begins. A third hypothesis is stimulation of this reflex. However, we observed an increase in the amplitude of accommodation without changes in the pupil diameter. This may be an indication that it was not due to muscarinic stimulation, with contraction of the ciliary muscle.

In fact, we believe, in our case, that, by some mechanism, there was direct brain stimulation. Studies shows that needle stimulation at acupuncture points activate brain areas. ${ }^{25}$ Some researchers ${ }^{26}$ used the association of acupuncture points LI4, L3, and ST36 for analgesia and demonstrated electrical activation of the somatosensory cortex after treatment. This finding was reproduced with use of points separated by other researchers. ${ }^{27}$ Needle insertion on the left wrist (TH5) stimulates the left side of the brain. ${ }^{28}$ This result is in accordance with triple heater meridian path that connects to the ipsilateral cerebral hemisphere. ${ }^{29}$ Being the TH-23 point of the same meridian, could it have some similar action? The ciliary muscle is innervated by the third cranial nerve, with most of the fibers coming from the Edinger-Westphal nucleus of the oculomotor complex through the ciliary ganglion. In cynomolgus monkeys, a bipolar stimulation electrode of the EdingerWestphal nucleus stereotaxically positioned generates maximum accommodative amplitud. ${ }^{30}$ So, ccould the gain of accommodation amplitude after needling of Sizhukong acupuncture point (TH23) be caused by stimulation of Edinger-Westphal nucleus? Finally, increase of blood perfusion of certain areas of brain ${ }^{26}$ could explain better vision at near. Studies in myopic patients ${ }^{31,32}$ show a transient refractive effect after acupuncture of certain points. ${ }^{33}$ These studies conclude relationship between visual acuity and brain blood perfusion. Could the stimulation of the acupuncture point activate blood perfusion of visual areas of the brain? After a careful bibliographical review, just conjectures remain for us, since the scientific literature simply does not present a plausible explanation for the increase in the amplitude of accommodation after stimulation of the acupuncture point $\mathrm{TH} 23$ (Table 4).

Table 4 The following table summarizes theoretical hypothesis we consider

\begin{tabular}{ll}
\hline & Theoretical hypothesis \\
\hline 01 & Lens dislocation \\
02 & Contraction of Ciliary Muscle \\
03 & Stimuli of Accommodation Reflex \\
04 & $\begin{array}{l}\text { Increasing of blood perfusion of brain } \\
\text { areas }\end{array}$ \\
\hline
\end{tabular}

\section{Conclusion}

We conclude this clinical case stating that, as the ancient books of acupuncture refer, the needling of the TH23 acupuncture point really can improve (although temporarily) vision at near. We think that great contribution of this report is to awaken the scientific community to perform new studies that can elucidate this result. We hope that it would be the beginning of a new era of understanding presbyopia and offering the presbyopic patient a physiological alternative than simple proposal of optical correction.

\section{Conflicts of interest}

None.

\section{Acknowledgments}

None.

\section{References}

1. Corrêa EJ Presbiopia. Correção clínica ou cirúrgica? Revista da Faculdade de Ciências Médicas de Sorocaba. 2008;10(2):28-29.

2. Duarte WR, Barros AJ, Dias-da-Costa JS, et al. Prevalence of near vision deficiency and related factors: a population-based study in Brazil. Cad Saude Publica. 2003;19(2):551-559.

3. Abrahamson IA. Eye changes after forty. American Family Physician 1984; 29(4):171-181.

4. Zamboni FJ, Uras R. Correção da presbiopia. Uras R. Óptica e refração ocular. Rio de Janeiro, Brazil. Cultura Médica; 2000:109.

5. Von Helmholtz H, Southall JPC. Treatise on physiological optics. Courier Corporation; 2005

6. Werner L, Trindade F, Pereira F, et al. Physiology of accommodation and presbyopia. Arquivos Brasileiros de Oftalmologia. 2000;63(6):487-493.

7. Sussmann DJ. Acupuntura: teoría y práctica: la antigua terapeútica china al alcance del medio práctico. Editorial Kier.1987.

8. Wen TS, Hing WT, Kumatsu MA. Manual terapêutico de acupuntura Barueri, SP, Manole, Brazil. 2008.

9. De Medeiros R, Saad M. Acupuntura. efeitos fisiológicos além do efeito placebo. O Mundo Da Saude Sao Paulo. 2009;33(1):69-72.

10. Fonseca RJDSD. Efeitos da acupuntura na dinâmica eletrofisiológica cerebral: Revisão Sistemática. 2017.

11. Nozabieli AJL, Fregonesi CEPT, Fregonesi DA. Correlação dos Canais de Acupuntura com a Neuroanatomia e a Neurofisiologia. Arquivos de Ciências da Saúde da UNIPAR. 2000;4(3)

12. Poletti A, Poletti JE, Franzini S. Oftalmologia em medicina tradicional chinesa e acupuntura. São Paulo, Andrei, Brazil. 1984.

13. Wong S, Ching R. The use of acupuncture in ophthalmology. Am J Chin Med. 1980;8(1-2):104-153.

14. Ullah N, Pal A. Diurnal change in amplitude of accommodation in adults. Ophthalmology Pakistan. 2016;6(02):29-32.

15. Kurtev AD, Stoimenova BD, Georgiev ME. Diurnal variations in tonic accommodation. Invest Ophthalmol Vis Sci. 1990;31(11): 2456-2458.

16. Anderson HA, Stuebing KK. Subjective vs Objective Accommodative Amplitude: Preschool to Presbyopia. Optom Vis Sci. 2014;91(11):1290 1301. 
17. Garrido FV, Muñoz FM. Needling techniques and modalities. Advanced Techniques in Musculoskeletal Medicine \& Physiotherapy-E-Book: using minimally invasive therapies in practice. 2015. p. 55.

18. Rosenfield M, Portello JK, Blustein GH, et al. Comparison of clinical techniques to assess the near accommodative response. Optometry \& Vision Science. 1996;73(6):382-388.

19. Cricenti SV. Localização anatômica dos pontos de acupuntura. 2nd ed. Brazil: Barueri, SP, Manole; 2011.

20. Fucks C. Atlas de acupuntura. Brazil: Barueri, SP, Manole; 2005.

21. Wang LG, Pai HJ. Tratado contemporâneo de Acupuntura e Moxibustão. Cemec: São Paulo; 2005.

22. Ma SX. Enhanced nitric oxide concentrations and expression of nitric oxide synthase in acupuncture points/meridians. J Altern Complement Med. 2003;9(2):207-215.

23. Abreu P, Meireles J. Monitorização Clínica no doente com lesão cerebral aguda. Intensive. 2011;18(3):49.

24. Mordi JA, Ciuffreda KJ. Static aspects of accommodation: age and presbyopia. Vision research. 1998;38(11):1643-1653.

25. Dhond RP, Witzel T, Hämäläinen M, et al. Spatiotemporal Mapping the Neural Correlates of Acupuncture with MEG. J Altern Complement Med. 2008;14(6):679-688.

26. Theysohn N, Choi KE, Gizewski ER, et al. Acupuncture-Related Modulation of Pain-Associated Brain Networks During Electrical Pain Stimulation: A Functional Magnetic Resonance Imaging Study. J Altern Complement Med. 2014;20(12):893-900.
27. Witzel T, Napadow V, Kettner NW, et al. Differences in cortical response to acupressure and electroacupuncture stimuli. BMC Neurosci. 2011;12(1):73.

28. Hsu SF, Chen CY, Ke MD, et al. Variations of brain activities of acupuncture to TE5 of left hand in normal subjects. Am J Chin Med. 2011;39(4):673-686.

29. Chen J, Wang J, Hang Y, et al. Modulatory effect of acupuncture at waigan (TE5) on the functional connectivity of the central nervous system of patients with ischemic stroke in the left basal ganglia. Plos one. 2014;9(6):e96777

30. Crawford K, Terasawa E, Kaufman PL. Reproducible stimulation of ciliary muscle contraction in the cynomolgus monkey via a permanent indwelling midbrain electrode. Brain Res.1989;503(2):265-272.

31. Garza Guerrero. RODOLFO Efecto inmediato de la estimulacion laser en yangbai (vb14) sobre la agudeza visual en sujetos miopes (doctoral dissertation). 2010

32. Val'kova IV, Niurenberg O. Use of electroacupuncture reflexotherapy in myopia. Vestnik oftalmologii. 1989;105(1):33-35.

33. Dabov S, Goutoranov G, Ivanova R, et al. Clinical application of acupuncture in ophthalmology. Acupunct Electrother Res 1985;10(12):79-93. 